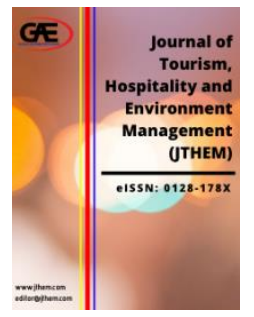

\title{
TO COOK OR NOT TO COOK; INTERNATIONAL STUDENTS' FOOD CHOICE STRATEGY
}

\author{
Eshaby Mustafa*1, Muhamad Shah Kamal Ideris², Noor Azimin Zainol ${ }^{3}$
}

1 School of Tourism, Hospitality and Event Management, Universiti Utara Malaysia (UUM), Malaysia Email: eshaby@uum.edu.my

2 School of Tourism, Hospitality and Event Management, Universiti Utara Malaysia (UUM), Malaysia Email: shahkamal@uum.edu.my

3 School of Tourism, Hospitality and Event Management, Universiti Utara Malaysia (UUM), Malaysia Email: azimin@uum.edu.my

\section{Article Info:}

\section{Article history:}

Received date: 28.01 .2020

Revised date: 06.02.2020

Accepted date: 09.02.2020

Published date: 15.03.2020

\section{To cite this document:}

Mustafa, E., Ideris, M. S. K., \& Zainol, N. A. (2020). To Cook or Not To Cook; International Students' Food Choice Strategy. Journal of Tourism, Hospitality and Environment Management, 5 (18), 88-98.

\section{DOI: $10.35631 / \mathrm{JTHEM} .518008$.}

\begin{abstract}
:
The important role of food choices in symbolic, economic and social aspects of life leads to the increased attention given to this area. This role became increasingly important and complicated for international students living in a foreign country for the first time, away from their families, as they are now required to make individual decisions on food choice. Therefore, the food choice strategy as practiced by the international students will receive dedicated attention to this study. This study is set within the academic environment at a local university in Northern Malaysia. Several qualitative methods such as indepth interviews and observation were used to assess the international students' food choice strategies and how the local food environment influences their food choice decision. Six international students took part in this study. The findings indicated that most international students resorted to preparing and cooking their own food, mainly to satisfy their cravings and as a cure to homesickness. The food choice strategy also depended on their level of knowledge in food preparation, convenience, and resources available to them. These finding advances the food choice decision process and explicates the food acculturation among international students in Malaysia. Moreover, the findings have direct implications for institutions' management of international students in assisting and improving their overseas experience.
\end{abstract}

Keywords:

Food Choice Strategy, International Students, Food Acculturation 


\section{Introduction}

Malaysia has become increasingly popular as a destination choice for international students. A 2014 UNESCO report highlighted five key reasons for international students to choose Malaysia as their educational destination; cultural comfort, cost, value for money, language of instruction and quality of life. Higher education costs in Malaysia are also cheaper compared with traditional destination countries such as the United States, Australia and Europe. It was also claimed that the quality of Malaysian higher education is good, which yield a growing perception that higher education in Malaysia represents value for money. According to the QS Best Student Cities 2019 survey, Kuala Lumpur was voted as the world's most affordable city for students for the third time in five years. In addition, education quality in Malaysia is recognized as being on the rise. In the recent QS World University Rankings by Subject 2017, Malaysian universities have gained rankings among the global top 50 for 11 subjects. This makes it crucial for higher institution provider to continue their effort in attracting more international students to pursue their education in Malaysia.

Education generates billions of dollars per year worldwide. Creating an education hub improves a country's workforce through knowledge generation, transfer, and retention. Moreover, educational hubs act as a growth engine. Entrepreneurs and state governments managing the colleges and universities can generate income out of the tuition fees and accommodation. Additionally, nations get to internationalize and modernize their education system. Apart from economic dependence, international students also contribute to the cross-cultural understanding and enhance sharing of ideas in the classroom setting. Therefore, university support is important for international student to develop a positive learning experience. This may help reduces all sort of stressors that students may experience when studying in the host country. Nonetheless, it was found in previous studies that less attention is directed to educational, social and cultural adjustment although the focus on these areas can support student adjustment to daily living and promotes a better learning experience (Perez-Encinas \& Rodriguez-Pomeda, 2018)

Universities play a crucial role in promoting healthier approach to food and further facilitate healthy eating choices among international students (Doherty et al., 2011). It was found that adjustment to food, along with academic stressors, may be important difficulty that international students face while studying in a foreign country (Hartwell et al., 2011). In addition, it was found that international students described food as one of the most problematic aspects of their stay in a new environment, as one of the examples of the difficulties faced during the initial phases of their stay (Capellini \& Yen, 2013). The university has huge potential to promote positive cultural and social adjustment in this area in order to improve the adjustment experiences for these students. However, there are scant studies that report the food adjustment experience and strategy of international students in Malaysia. Hence, this paper is aimed to explore international student food choice strategy in and to identify how the local food environment in Malaysia influence their food choice decision.

\section{Literature review}

\section{International Students' Food Choice}

Despite the growing sense that student services matter, very little research has shown exactly what international students desire and expect from support services (Kelo, Roberts, \& Rumbley, 2010). In this context, Bianchi (2013) identifies the provision of two types of services that are important to international students: core (which are related to teaching and 
learning) and peripheral (those related to the living conditions and the environment of the host country, such as security, cultural and social activities, accommodation, transportation, and visa/entry requirements). However, less attention was given towards the organizational elements related to support services, and student needs and perceptions. Edwards, Hartwell and Brown (2010) mentioned that reshaping food consumption patterns in the new environment is a source of anxiety and the food that international students eat has great significance both physically and emotionally. International students will tend to make many changes in their new life at the university but are reluctant to change their eating habits and practices (Brown, 2009). Moreover, international students will be inclined towards preserving the food that made them feel closer to home. It was found that international students preferred having familiar home country food and will choose popular global brands when making food choice decision (Bengtsson et al., 2010, Chang et al., 2010, Osman et al., 2014).

Food from home represents a symbol of belonging, a healthy lifestyle and the maintenance of social relationships with fellow international friends (Bardhi, Ostberg, \& Bengtsson, 2010). Consequently, host country food will remain unfamiliar to the students and will not be considered for consumption or purchased regularly (Bengtsson et al., 2010). For international students, migration became an important turning point as the start of a new independent life and new responsibilities in the host country. This experience became more challenging because the students are required to develop a new food choice system and were constantly being expose to unfamiliar food and culture, alongside personal commitment to food provisioning responsibilities, which added to the stressful academic roles and activities (Mustafa, 2016).

\section{Food Choice Adjustment Strategy}

Various strategies were commonly formed when making food choices. Previous studies explained that the behavioural plans, routines and rules were the strategies developed to simplify food choices by eliminating the effort and time required when considering every food choice decision (Falk et al., 1996; Sobal et al., 2006). People used strategies when making food choices and the combination of strategies that are used have been described as a repertoire (Sobal et al. 2006). Table 1 presents a list of strategies to simplify food choice adapted from Falk et al. (1996) and Sobal et al. (2006);

\begin{tabular}{|l|l|}
\hline Strategy & Example \\
\hline $\begin{array}{l}\text { Focusing on one value } \\
\text { (emphasize only on cost, taste, health, } \\
\text { relationships, convenience or another } \\
\text { value) }\end{array}$ & $\begin{array}{l}\text { Eat the cheapest food whenever } \\
\text { Routinization } \\
\text { (standardized, systemized, routinized) }\end{array}$ \\
\hline $\begin{array}{l}\text { Elimination } \\
\text { (avoid, exclude, prohibit) }\end{array}$ & Eat cereal every day for breakfast \\
\hline $\begin{array}{l}\text { Limitation } \\
\text { (restrict, regulate, reduce) }\end{array}$ & Never eat desserts \\
\hline $\begin{array}{l}\text { Substitution } \\
\text { (replace, exchange, fill in) }\end{array}$ & $\begin{array}{l}\text { Drinks only two cups of coffee } \\
\text { everyday }\end{array}$ \\
\hline $\begin{array}{l}\text { Addition } \\
\text { (augment, include, enhance) }\end{array}$ & $\begin{array}{l}\text { Choose brown rice instead of white } \\
\text { rice }\end{array}$ \\
\hline $\begin{array}{l}\text { Modification } \\
\text { (alter, adjust, transform) }\end{array}$ & Eat a salad with every evening meal \\
\hline
\end{tabular}

Table 1-Strategies for Simplifying Food Choices 
The strategies in Table 1 are explained further; (1) Focusing on one value discounts other values as less relevant and defines a food choice setting in a way so that values do not have to be negotiated.; (2) Routinization standardizes food choice decision- making processes or actual eating behaviours for a recurring situation into habits and automatic behaviours; (3) Elimination excludes particular foods, food categories, eating location or eating patterns from all food choice options or make exclusion for particular setting; (4) Limitations restricts use of selected foods or ways of eating to simplify food choice decisions, but is more complex than elimination because it requires establishing acceptable levels and then monitoring adherence to those limits; (5) substitution replaces food or ways of eating to accommodate conflicting values by replacing one option with another that is more satisfactory (Sobal et al. 2006). These strategies are important in evaluating the students' food choice decision and practices in the host country.

Falk et al. (1996), Furst et al. (1996), Connors et al. (2001), and Sobal et al. (2006) explained that the behavioural plans, routines and rules were the strategies developed to simplify food choices by eliminating the effort and time required when considering every food choice decision. Sobal et al. (2006) commented that strategies emerged from initial conscious food choice decisions for a specific situation and eventually become less mindful when that situation repeated in future. The multiple uses of strategies and the personal set of strategies constitute a repertoire (Falk et al. 1996; Sobal et al. 2006). Repertoires may include use of 'one dominant strategy, simultaneous use of several strategies, sequential use of different strategies, and situational use of strategies to make food choice decisions' (Sobal \& Bisogni, 2009:pg43). This study will attempt to assess the strategies developed by the international students and relate them to the strategies proposed by Falk et al. (1996) and Sobal et al. (2006).

\section{Cooking As Food Choice Strategy for International Students}

The transition to an independent living in a new country can be explained as a specific point of 'transition in practice' especially for new international students. This is the point when they can shape competencies and ways of doing things for later life through the newfound responsibilities of provision and preparing food independently (Clear et al., 2013). Caraher, Dixon, Lang and Hill (1999) found that poor cooking skills are a barrier to widening food choice and reduced the chance of healthy eating. For the international students, cooking was considered the best way to fulfil cravings for home country food and saving more money compared to the cost of eating out.

It was found that students, who had the least problem with unfavourable eating habits, were the students who are experienced cooks from home (Blichfeldt et al., 2013). Cooking their own food did not seem to be an issue among the international student, as it showed a $62.5 \%$ increase in the frequency of cooking upon living in the new country (Alyousif \& Mathews, 2018). However, a general lack of specific cooking techniques and confidence to cook certain foods remain a challenge for the international students.

\section{Study Method}

This paper reports the second part of a project on international students' food related experience in Malaysia. This study employed qualitative method for the main study. An observation and in-depth interview were adopted, and the data were analysed using thematic analysis. The qualitative approach to explore the food choice strategy was appropriate and fit with the purpose, aim and objectives of this study. Moreover, this study is concern with the lived 
experiences of international students when deciding food choice to understand the decisionmaking process. A qualitative approach is the most appropriate to address the issue. Purposive sampling technique was employed to recruit international students from a local university in Northern Malaysia. Given the limited number of participants, this paper does not pretend to provide an analysis that is representative of all international students in Malaysia. This study would simply provide an in-depth analysis on the international students' food choice strategy from those who are enthusiastic about food and are willing to speak about their food preference, habits and behaviour during their stay in Malaysia. Six international students took part in this study, as shown in Table 2 next.

\begin{tabular}{ccc}
\hline Pseudonyms/ Gender & Country of origin & Age \\
\hline A $(\mathrm{F})$ & China & 22 \\
B $(\mathrm{M})$ & Indonesia & 23 \\
C $(\mathrm{F})$ & Indonesia & 21 \\
D $(\mathrm{F})$ & Thailand & 22 \\
E $(\mathrm{F})$ & Yemen & 30 \\
F $(\mathrm{F})$ & Saudi Arabia & 24 \\
\hline
\end{tabular}

Table 2: Participants' Demographic and Social Characteristics (n:6).

In total, the students consist of one from China, two from Indonesia, one from Thailand, Yemen, and Saudi Arabia respectively. Age range is from twenty-two to thirty years old. Five female and only one male student were observed and interviewed.

An observation was intended as an opportunity to observe how the students conduct their food preparation. During the observation, the researcher visited the participant's kitchen or food preparation area and took notes based on the condition. Since some of the students do not have an actual kitchen area, most observation took place in the makeshift area within the student's residential. The objective was to observe the resources when preparing food in a new setting and environment. A semi-structured interview was conducted after the observation. It allowed the researcher an opportunity to understand the observation notes. It also allows the participant's actions to be translated into the form of contextual data fitting the objectives of this study. The interview was also conducted to capture an in-depth explanation, personal experience, issues and perception as well as to deepen the meaning of the student's food choice practice in the new country. All the interviews were then transcribed verbatim, coded and analysed using thematic analysis.

\section{Findings}

The transition from living at home to independent living requires the international students to undertake both the role in academic life, as well as the responsibilities of food provisioning practices like grocery shopping, preparing and cooking, something that some of the students had never dealt with before. Furthermore, the challenge of undertaking the new role within an unfamiliar environment, new food choices to consider and being inexperience added the stress to the adjustment experience.

'I never cook before but now I have learned more recipes and I use one for each day. It's difficult for me at first' (E).

Respondent E found that the lack of cooking skills meant she had limited food choice. She was determined to cook her own food eventually, for several reasons; to save money and 
to fulfil her cravings. Respondent $\mathrm{E}$ admitted that she ate out at the university's cafeteria every single day. She just recently decided to prepare her own food, because she realized that outside food was unhealthy and not to her liking. She expressed her dissatisfaction and was unable the accept the food.

Respondent D on the other hand, was able to cope with the food available around the university because of the familiar taste. The location of the university, which has proximity to the Thai and Malaysia border, has created a foodscape that is similar to her home countries. Although the food was perceived as acceptable, she would cook almost all the time due to the availability of familiar ingredients to make Thai food.

'I can cook easy recipes. It is easy to make them and ingredients are easily available in the market. I cook mostly Thai food' (D).

In the case of respondent, $\mathrm{A}$, she had more instant ready meals when she first arrived in Malaysia. She brought along with her packs of instant noodles and alike in her bag and she was consuming them for the first two weeks in Malaysia. She bought a small electric cookpot, as there was no kitchen in the dormitory. She would cook instant noodle in her room that she shared with her roommate who was also from China. Although cooking was not allowed, this was the only food she was comfortable with at the beginning.

'I have a lot of instant noodle. All with Chinese taste. I have only a water heater (kettle) before. Now we have this (electric cookpot) and we can add more ingredients and vegetable' $(A)$.

The ability to develop personal food provisioning skills, especially cooking, was also a channel to relieve adjustment stress during the arrival phase. Cooking his own food also worked like a therapy during stressful times for respondent B. He admitted that although he had no prior cooking skills, the experience made a change in his life as a new international student and a sign of independent living.

'Only my mom cooks at home. Now I am in charge and I have to cook. I can learn a lot from YouTube. I have to ask my Malaysian friend to take me to buy ingredients, but I can know most item now' (B).

In addition, Participant $\mathrm{B}$ also watched and learnt new recipes from cooking shows on YouTube. He would then take photos and shared them on social media, such as Facebook, Instagram or WhatsApp and dedicated the post especially to his mother.

In addition, cooking session also provided the opportunity for social interaction with other international students. Brown's (2009) study mentioned the use of food as a social agent through cooking activities with co national friends or sharing food with other nationalities.

'Every Friday I will have a gathering with my friends, and we will cook the food and have a party. I feel like I am back at home and it made me happy. I always look forward to Friday' $(F)$.

Cooking a meal with extended and complicated recipes as well as other home style food, was reserved for the weekends, commonly with co-national friends, when they had more time to spend in the kitchen. Nevertheless, the new students preferred to cook traditional ethnic dishes 
when they had friends coming over. The pride in sharing the authentic taste of their national dishes had become a symbol for self-identity and gave a sense of belonging.

I am really proud of Thai food and I would cook Thai food for my friends and roommate. They also say it is delicious' (D).

The international students also felt they have not much choice when it comes to preparing food because most dormitory have shared kitchen and they cannot cook regularly. There was also limited space in the shared fridge to keep food ingredient. They felt at times they were forced to have food sold at the university cafeteria.

'The food in the café is mostly Malaysian food. There is only one place that sell Middle East food and I have to go by bus. I have to share the kitchen and not enough space to put the meats and other ingredients in the fridge' $(E)$.

The student felt she could get better food by cooking them herself. However, her intention was limited by the shared kitchen where she needs to share with another 20 students on the same floor. She felt that the fridge and freezer usage are very critical for her when making homemade food, but the space is also limited.

It was found that the obstacles commonly related to home food preparation and cooking was finding the traditional, ethnic ingredients. Respondent $\mathrm{E}$ claimed it was easy to find ingredients in the supermarkets but sometimes it tastes differently.

'Yes, they are sold in supermarkets but different flavour. The meat is different, the spices too' $(E)$.

Respondent E hence brought varieties of food from Yemen when she came to the country.

'I bring with me all spices to make the rice and marinades. This has more similar taste to me' $(E)$.

The reported findings about the perceived 'different' taste of ethnic food ingredients or familiar food available in the host country implicated the strong connection of sensory appeal of the ethnic food and acceptance of the food available in the host country.

Mehdizadeh et al., (2005) study on Iranian international students in Scotland stated that issues like finding food items or ingredients that the students were an issue to international students. This is because ethnic food stores selling imported cooking ingredients were increasingly available and even local supermarket had supplies of such ingredients. Vallianatos et al. (2008) found that the availability of ethnic food stores was like a haven for migrants where they can find the comfort of familiarity from the same food products with the same packaging as back home. The availability of ethnic food ranges in large supermarket chains attempting to meet the diverse population's needs made it easier to re-create ethnic traditional cuisine (Vallianatos et al., 2008). This means that the access to the authentic ingredients to re-create a home country meal was becoming much easier. It was found that if the home food ingredients were not available in the local stores, the students learned to improvise the recipe in order to achieve the taste. 
Modifying the method of cooking, adding ethnic spices or sauces were introduced to make the dish more palatable and less foreign; thus, changing the symbolic meanings of the food (Vallianatos et al., 2008). The improvisation process, according to Fischler (1988), means the food becomes more familiar, less threatening and more acceptable. The individual the students in their food choice asserted connotations of new independent living, ethnicity and religion during grocery shopping, eating out and food preparation.

Furthermore, perceived inadequacy of appliances for food preparation and food selection in local stores, cooking skills, money to buy food, and time available for food preparation were perceived as inadequate and were barriers to food preparation for a minority of young adults (Larson, Perry, Story \& Neumark-Sztainer, 2006). The challenges of food preparation can be a real burden especially to the new international students due to these obstacles. Nonetheless, enough aid was received for food procurement with the help of new friends. Cooking appliances were normally inheritance from the seniors. Having the cooking sets also gave ideas on making different food and made the task much easier.

'I have a lot of pots and chopping boards and knife sets from my seniors. I don't think about cooking before but now I have all this, I will cook more' (D).

Recreating traditional ethnic dishes was common, but the students admitted they enjoyed trying other international recipes the most because they never had a lot of opportunity to do so back in their home country. The choice of food the students made ranged from the simplest of a dish, to the most elaborate recipes. The freedom of living independently appeared to be celebrated through cooking.

I cook Pad Thai. My Thai friend cook for me once and I went to buy the ingredients and try by myself. It's not the same taste but acceptable to me. I will try other Thai food $(C)$.

\section{'We made sushi and some Korean food. Next we will try some Malaysian fried rice' (A).}

The various international cuisine tried and tested by the students were sometimes influenced by their circle of new international friends. It was agreed that eating familiar traditional home food was comforting, fulfilling and helped alleviate loneliness. However, preparing and cooking international cuisine showed acceptance and appreciation towards other cultures around them and indicated a multiculturalism approach of adjustment.

The food choice decision when the students first arrived relied heavily on the recommendations, habits and practices of other co national friends when they first arrived, previous food provisioning experience and the availability of familiar foods. The Malaysian food and culture experiences were very limited and friendship network with the locals were almost non-existent. Most of the new international students showed their willingness to try new food whenever possible; including local Malaysian food that are widely available at the university's cafeteria. The international students have the chance to explore a lot of different new food. When asked to describe their perception towards local Malaysian food, words like 'cheap', 'unfamiliar taste', 'unhealthy', 'spicy', 'frozen food', 'fried food', and 'available 24 hours' were often used. On a more positive note, most of the international students claimed to be eating more fruits in Malaysia. 


\section{Discussion}

The international students expressed their excitement to undertake their new role and responsibilities in food choice decision because it was a chance for them to personalize a set of habits and practices. It was noted how lively the students were when they discussed about their new food choices, their plans for food purchase, the kitchen utensils they bought, buying fresh ingredients, showing off photos of the food they made and discussing the exciting new recipes they wanted to try in the future. Overall, they were excited and expressed determination to practice cooking and they were looking forward to learning and develop this new set of skills. Although there were still a lot more to know about managing food provisioning responsibilities, the students seemed to be eager and coping well with the task. In addition, the cooking facilities provided at some of the students' dormitories were not enough to cater to all.

Inevitably, the biggest challenge related to food preparation and cooking is to prioritize between the various tasks as a student and personal life within the scarce time and resources and this echoes the study by Blichfeldt et al. (2013). The experience of the new international students in managing their food preparation and cooking during the transition suggests the importance of acquiring competencies and skills to a successful adjustment to the new food choice and culture. It was also an opportunity for the students to express their creativity and ability in their new life, away from parental and family control. Most of the students showed enthusiasm to prepare and cook a meal and showed it off to their family and friends back home. Significantly, the students felt proud that they were able to manage the new task, which was commonly perceived as a sign of maturity and independent living.

International students who had prior experience in cooking and preparing food allowed them to choose familiar, fresher and healthier food ingredients. Depending on the experience, skills and competencies acquired, the students enjoyed preparing their own home country food, which to them are much more fulfilling. The international students believed that by cooking, it gave them the opportunity to be in control of their own personal decision of food choice and started to consider ethical food consumption and concern over healthy and body appearance. It showed a level of maturity, freedom and the demanding commitment of food choice responsibilities. It also allows them to try foods that were often restricted in their home and explore new food choices.

International students were less willing to try new foods because they could be in a negative mood state of anxiety, depression, loneliness and stress which was found to be at the most intense at the beginning of the course during the transition (Ward et al., 2001). However, in this study, the new international students showed excitement, willingness and acceptance of new foods and other international cuisines, despite the unfamiliar taste, not only when they were cooking but also when eating out. Interestingly, the international students would also experiment other international food; for instance, Thai food, Korean, Japanese, Italian, Chinese as well as other Western cuisines.

\section{Conclusion}

This study offers contribution using observation and interview method that enabled the explanation and gave meaningful context of each stage that required international students' food choice decisions. Evidently, this study demonstrated that transition and turning point in the international students' migration has a major impact on their food choice system. The findings support the theory of acculturation strategy whereby it was learned that the international students made conscious decisions to improve their personal self-efficacy, and skills and competencies in food provisioning in response to independent life in a new country. 
The new life of international students demanded changes and commitment in roles and responsibilities, resources, and context that is disruptive to the usual or established personal food systems and lead to reconstruction of food choice pattern and consequently, food acculturation.

The findings from this study may assist the university in constructing a more relevant policy and services that support the food adjustment and different needs of international students. Identifying the key influences in shaping the students' food choice may improve healthy eating practices. The findings may inform the support services on the food related challenges faced by the international student during the early stage of their transition especially on the adjustment stress concerning food-provisioning tasks, undertaking the new roles and responsibilities of a new independent living and guidance and support in managing a healthy lifestyle. The food suppliers and providers in and around the university may benefit from this study through the understanding of the availability and accessibility of healthy, affordable, and preferred foods, dietary restrictions and other factors that may limit the accessibility to wider food choices in Malaysia. It will assist in providing food choice that serves the diverse needs of every international student. The study also benefits potential international students in their consideration of Malaysia as their study destination.

\section{References}

Alyousif, Z., \& Mathews, A. E. (2018). Impact of migration on diet, physical activity, and body weight among international students moving from the Gulf Countries to the United States. Case Rep. J, 2(7).

Bardhi, F., Ostberg, J., \& Bengtsson, A. (2010). Negotiating cultural boundaries: Food,travel and consumer identities. Consumption, Markets and Culture. 13(2), 133157.

Bianchi, C. (2013). Satisfiers and dissatisfiers for international students of higher education: An exploratory study in Australia. Journal of Higher Education Policy and Management, 35(4), 396-409.

Bengtsson, A., Bardhi, F., \& Venkatraman, M. (2010). How global brands travel with consumers: An examination of the relationship between brand consistency and meaning across national boundaries. International Marketing Review, 27(5), 519-540.

Blichfeldt, B. S., \& Gram, M. (2013). Lost in transition? Student food consumption. Higher Education, 65(3), 277-289.

Brown, L. (2009). The role of food in the adjustment journey of international students. The new cultures of food: Marketing opportunities from ethnic, religious and cultural diversity, p.p. 37-56.

Brown, L., Edwards, J., \& Hartwell, H. (2010). A taste of the unfamiliar. Understanding the meanings attached to food by international postgraduate students in England. Appetite. 54(1), 202-207.

Cappellini, B., \& Yen, D. A. W. (2013). Little Emperors in the UK: Acculturation and food over time. Journal of Business Research, 66(8), 968-974.

Caraher, M.; Dixon, P.; Lang, T.; Carr-Hill, R. (1999): The state of cooking in England. The relationship of cooking skills to food choice. British Food Journal, 101, 590-609.

Chang, R. C., Kivela, J., \& Mak, A. H. (2010). Food preferences of Chinese tourists. Annals of Tourism Research, 37(4), 989-1011.

Clear, A., Hazas, M., Morley, J., Friday, A. and Bates, O. (2013). Domestic Food and Sustainable Design: A Study of University Student Cooking and its Impacts. In: Proc. CHI 2013, ACM 2447-2456. 
Connors, M., Bisogni, C. A., Sobal, J., \& Devine, C. M. (2001). Managing values in personal food systems. Appetite, Vol. 36 (3) p.p. 189-200.

Doherty, S., Cawood, J., \& Dooris, M. (2011). Applying the whole-system settings approach to food within universities. Perspectives in Public Health, 131(5), 217-224.

Falk, L. W., Bisogni, C. A. \& Sobal, J. (1996). Food choice processes of older adults: A qualitative investigation. Journal of Nutrition Education and Behaviour, Vol. 28 (5) p.p. 257-265.

Fischler, C. (1988). Food, self and identity. Information. International Social Science Council, 27(2), 275-292.

Furst, T., Connors, M., Bisogni, C. A., Sobal, J. \& Falk, L. W. (1996). Food choice; a conceptual model of the process. Appetite, Vol. 26 p.p. 247- 266.

Hartwell, H. J., Edwards, J. S., \& Brown, L. (2011). Acculturation and food habits: lessons to be learned. British Food Journal, 113(11), 1393-1405.

https://www.studymalaysia.com/education/top-stories/qs-world-university-rankings-bysubject-2019

https://www.topuniversities.com/city-rankings/2019

http://www.unesco.org/new/en/santiago/resources/singlepublication/news/annual_report_201 4/

Kelo, M., Rogers, T., \& Rumbley, L. E. (2010). International student support in European higher education: Needs, solutions, and challenges. Lemmens Medien.

Larson, N. I., Perry, C. L., Story, M., \& Neumark-Sztainer, D. (2006). Food preparation by young adults is associated with better diet quality. Journal of the American Dietetic Association, 106(12), 2001-2007.

Mehdizadeh, N., \& Scott, G. (2005). Adjustment problems of Iranian international students in Scotland. International Education Journal, Vol. 6 (4) p.p. 484-493.

Mustafa, E. (2016). Food acculturation of new international students in the UK (Doctoral dissertation, University of Surrey).

Osman, I., Osman, S., Mokhtar, I., Setapa, F., Shukor, S. A. M., \& Temyati, Z. (2014). Family food consumption: desire towards convenient food products. Procedia-Social and Behavioral Sciences, 121, 223-231.

Perez-Encinas, A., \& Rodriguez-Pomeda, J. (2018). International students' perceptions of their needs when going abroad: Services on demand. Journal of Studies in International Education, 22(1), 20-36.

Sobal, J., Bisogni, C. A., Devine, C. M., \& Jastran, M. (2006). A conceptual model of the food choice process over the life course. The Psychology of Food Choice. In Shepherd, R. \& Raats, M. M. (Eds.) Vol. 3 (1) p.p. 1- 18. CABI Publishing.

Sobal, J. \& Bisogni, A. (2009). Constructing food choice decisions. Annals of Behavioural Medicine, Vol. 38 p.p. 37- 46.

Vallianatos, H., \& Raine, K. (2008). Consuming food and constructing identities among Arabic and South Asian immigrant women. Food, Culture \& Society, 11(3), 355-373.

Ward, C. (2001). The A, B, Cs of acculturation. The handbook of culture and psychology, 411445. 